\title{
Impaired metabolic control and socio- demographic status in immigrant children at onset of Type 1 diabetes
}

\author{
U. Soderstrom, Ulf Samuelsson, L. Sahlqvist and J. Aman
}

Linköping University Post Print

Tweet

N.B.: When citing this work, cite the original article.

Original Publication:

U. Soderstrom, Ulf Samuelsson, L. Sahlqvist and J. Aman, Impaired metabolic control and socio-demographic status in immigrant children at onset of Type 1 diabetes, 2014, Diabetic Medicine, (31), 11, 1418-1423.

http://dx.doi.org/10.1111/dme.12511

Copyright: Wiley: 12 months

http://eu.wiley.com/WileyCDA/

Postprint available at: Linköping University Electronic Press

http://urn.kb.se/resolve?urn=urn:nbn:se:liu:diva-112622 
ulfsod

$07 / 01 / 2015$

\section{Impaired metabolic control and socio-demographic status in immigrant children at onset of type 1 diabetes}

Ulf Söderström MD ${ }^{123}$, Ulf Samuelsson MD PhD ${ }^{5}$, Lotta Sahlqvist², Jan Åman MD PhD ${ }^{14}$

\footnotetext{
${ }^{1}$ School of Health and Medical Sciences Örebro University, Sweden

${ }^{2}$ Centre for Clinical Research Sörmland, Uppsala University, Sweden;

${ }^{3}$ Department of Pediatrics, Mälarsjukhuset Hospital, Eskilstuna, Sweden,

${ }^{4}$ Department of Pediatrics Örebro University Hospital, Sweden

${ }^{5}$ Division of Paediatrics, Department of Molecular and Clinical Medicine, Linkoping University, Sweden ${ }^{6}$ Department of Pediatrics, the University Hospital in Linköping, Sweden
}

\section{Abstract}

The aim of the present study was to compare clinical and socio-demographic conditions at the onset of type 1 diabetes in children born to immigrant families and children born to Swedish families, and to assess whether those conditions had an impact on metabolic status.

Design: Observational nationwide population-based matched cohort-study on prospectively recorded registry data.

Setting: All children with diabetes in Sweden and their families during $2000-2010$.

879 children born to immigrant parents out of a total of 13415 children from the Swediabkids registry were collected. To these we added 2627 children with Swedish-born parents, matched for gender, age and year of onset.

Results

The proportion of low capillary $\mathrm{pH}(<7.30)$ at onset was higher in the immigrant cohort, 25.8 $\%$, vs $16.4 \%$ in the Swedish cohort $(\mathrm{p}<0.001)$. $\mathrm{HbA}_{1 \mathrm{c}}$ was also higher, $95 \mathrm{mmol} / \mathrm{mol}(10.8$ $\%)$ vs $88(10.2 \%)$, respectively ( $\mathrm{p}<0.001)$. In a logistic regression model with low $\mathrm{pH}$ as the 
dependent variable we were unable to reveal any significant association to socio-demographic factors, but the OR for $\mathrm{HbA}_{1 \mathrm{c}}$ was 0.983 (95\% CI 0.976 - 0.991) and the OR for plasma glucose was $0.953(95 \%$ CI $0.933-0.973)$.

\section{Conclusion}

Children born to immigrant parents have lower capillary $\mathrm{pH}$ and higher $\mathrm{HbA}_{1 \mathrm{c}}$ at diabetes onset. Immigrant families harbour lower socio-demographic living conditions, but this fact does not seem to influence the inferior metabolic condition at diabetes onset.

Key words: diabetes type $1, \mathrm{HbA}_{1 \mathrm{c}}$, children, adolescents, ethnology, immigration

\section{Introduction}

The annual incidence of diabetes mellitus type 1 (T1D) in children varies considerably among different populations in the world [1]. Finland and Sweden have very high incidence rates. Incidence is considerably lower in southern Europe, and is lowest in Asia and Latin America. T1D is a fairly rare disease in East Asia. A secular trend towards increasing incidences has been reported from many high and middle income countries [2-4]. This has been accompanied by a shift to a younger age at onset in Sweden, now also seen in other countries $[2,5]$.

The aetiology of T1D is probably due to a complex interaction between genetics, environment and lifestyle, mediated by an autoimmune process leading to destruction of the insulinproducing beta cells in the endocrine pancreas and ultimately to a complete lack of endogenous insulin $[6,7]$.

\section{Migration as a natural experiment}

During recent decades, significant numbers of immigrants have moved to Sweden from regions where the incidence of T1D is considerably lower. In a previous study we showed that children born in Sweden into these families have a much lower risk of T1D compared to their indigenous Swedish peers [8]. We have also seen that the impact of being born in Sweden into 
these families increases the risk of T1D in offspring [9]. This same finding of increased risk for immigrant children to incur diabetes, if being born in a western country, was confirmed by another Swedish study focusing on genetics and an Italian study focusing on age at onset [10, $11]$.

The aim of the present study was to compare clinical and socio-demographic conditions at T1D onset of children born to immigrant families and children born to Swedish families, and to assess whether those conditions had an impact on metabolic status.

The principal, but complex, exposure in this study differentiating the two groups of children is migration of the parents.

\section{Methods}

Design: Observational nationwide population-based matched cohort-study on prospectively collected registry data.

Setting: According to Swedish national guidelines for childhood diabetes, every child with symptoms of diabetes is referred to a paediatric clinic for hospital treatment for approximately one week In Sweden, paediatric departments treat all children and adolescents aged 0 to 18 years with diabetes within their catchment areas. Outpatient attendance data from all Swedish paediatric diabetes centres $(n=43)$ are registered in the National Quality Registry for

Paediatric Diabetes in Sweden - Swediabkids, which was established in $2000[12,13]$. The completeness of centres reporting data increased from $32 \%$ to $100 \%$ from 2000 to 2007 . Thus the registry includes data on almost all (around 99\%) of the children and adolescents with diabetes in Sweden. Up to the end of 2011, the registry includes data from more than 315000 outpatient visits. In addition, in 2008 we found complete concordance with reports to the Swedish Diabetes Registry. This register is estimated to have completeness close to $100 \%$. In all 13415 children and adolescents were registered in Swediabkids from 2000 to 2010. From this registry we collected every patient with non-Swedish background, i.e. both parents are 
born outside Sweden. We found 879 (6.6\%) children with diabetes to immigrant families (Immigrant cohort). The overall proportion of people in Sweden with this background is $20 \%$ of whom 380000 are children ( $0-17$ years). To this cohort of 879 children we added 2627 Swedish children from the same registry, for whom both parents are born in Sweden, three for each immigrant child (Swedish cohort). The individuals from the two cohorts were matched according to gender, age and year of diabetes onset. Socio-demographic data were collected from Swedish national registers held by Statistics Sweden. All Swedish residents are assigned a unique 10-digit ID number at birth or immigration, personal identification number (PIN) [14]. This PIN was used to link information from different registry sources. The PINs were replaced by consecutive numbers, thereby concealing the identity of the patients to all investigators. All collected data relate to the date of T1D onset of each child. Height and weight were measured, and BMI was calculated and expressed according to Swedish national reference data [15]. Glucose was measured in plasma; $\mathrm{pH}$, standard bicarbonate and $\mathrm{HbA}_{1 \mathrm{c}}$ were measured in capillary blood. All blood tests were done at arrival to the hospital before start of insulin treatment. $\mathrm{HbA}_{1 \mathrm{c}}$ values are presented in IFFC units $(\mathrm{mmol} / \mathrm{mol})$, followed by NGSP units (\%), in parentheses: $58 \mathrm{mmol} / \mathrm{mol}$ (IFCC) corresponds to 7.5\% (NGSP) [16]. All paediatric diabetes centres in Sweden participate in Equalis, External Quality Assurance in Laboratory Medicine in Sweden, for external quality assessment of clinical laboratory investigations $[17,18]$.

\section{Ethics}

This study was approved by the Regional Ethics Committee in Stockholm.

\section{Statistics}

Clinical characteristics of children with type 1 diabetes at onset are described with median and inter-quartile range, while the variables are non-normally distributed (Table 1). Maternal socio-demographic status is described with percentages (Table 2). Ordinal and non-normally 
distributed continuous data were analyzed using Pearson Chi-square test or Mann Whitney Utest.

Multiple logistic regression models were used to estimate associations between biological and socio-demographic data as independent variables, and $\mathrm{pH}<7.30$ at onset as the dependent variable. Statistical significance was defined by $\mathrm{p}<0.05$ (2-sided).

Data were analysed by using IBM SPSS Statistics 20.0, Armonk; NY; USA.

\section{Results}

Clinical and socio-demographic data from diabetes onset were collected and compared between the two cohorts. The proportion of girls among the children with diabetes was higher in the immigrants $(49.1 \%)$ in relation to the whole diabetes population $(45.7 \%), \mathrm{p}=0.049$. Paternal age was higher in the immigrant group, but no obvious difference was observed for maternal age. Median BMI-sds was lower in the Swedish cohort $(\mathrm{p}=0.027)$ and there was a tendency towards a greater proportion of weight loss $(p=0.054)$. There was no difference in plasma glucose at onset. The proportion of low capillary $\mathrm{pH}(<7.30)$ was higher in the immigrant cohort, $26 \%$ vs. $16 \%(\mathrm{p}<0.001)$. The immigrant children had lower median capillary $\mathrm{pH}$ of 7.35 vs. $7.37(\mathrm{p}<0.001)$ and a corresponding difference was seen for bicarbonate. $\mathrm{HbA}_{1 \mathrm{c}}$ was higher in the immigrant group, $94 \mathrm{mmol} / \mathrm{mol}(10.8 \%)$ vs. 88 (10.2 $\%)(\mathrm{p}=0.005)($ Table 1$)$

There were considerable inequalities for socio-demographic conditions in almost every aspect. The parents of the immigrant children comprised more single parents, were less well educated, needing more social welfare, were often unemployed and lived in renting accommodations. The number of children differed between the two cohorts as did the birth order (Table 2).

The numbers and the region/country of origin of the immigrant parents and their children are shown in table (Table 3). The majority, 641 (72.9\%), of the children born into the immigrant 
families, were born in Sweden. Besides the Nordic countries Iraq, former Yugoslavia and Somalia have a considerable number of immigrants in Sweden according to national demographic data from Statistics Sweden.

When comparing girls to boys within the cohorts, we were unable to discern any disparities according to low capillary $\mathrm{pH}$. However, for $\mathrm{HbA}_{1 \mathrm{c}}$, there was a gender difference among the Swedish children, girls having higher $\mathrm{HbA}_{1 \mathrm{c}}, 90$ vs. 87 for boys $(\mathrm{p}=0.032)$.

In a multiple logistic regression model using $\mathrm{pH}<7.30$ in capillary blood as the dependent variable, testing for socio-demographic factors, type (Immigrants/Swedes) was the only significant outcome, OR 1.776 (95\% CI 1.339 - 2.357). In a similar model with the same dependent variable, tested for both social and clinical variables, the outcomes were OR 1.797 (95\% CI $1.196-2.700)$ for type, OR 0.953 (95\% CI 0.933 - 0.973) for plasma glucose and OR $0.983(95 \%$ CI $0.976-0.991)$ for $\mathrm{HbA}_{1 c}$.

\section{Discussion}

According to annual reports from the Swediabkids registry more than $97 \%$ of all diagnosed diabetes among children and adolescents in Sweden is type 1, confirmed by immunological and genetic studies $[19,20]$. Immigrants change environment, and perhaps lifestyle, influencing an altered risk of developing diseases for themselves and their offspring. The present study indicates that children born to immigrant families in Sweden have worse metabolic status at diabetes onset compared to children of Swedish descent according to capillary $\mathrm{pH}$, bicarbonate and $\mathrm{HbA}_{1 \mathrm{c}}$, but not plasma glucose and BMI- SDS. A high $\mathrm{HbA}_{1 \mathrm{c}}-$ value from start or during the first year of treatment predisposes future poor control and thereby increases the risk for late complications [21-24]. The figures found for low $\mathrm{pH}$ in the Swedish children were equivalent to those in an earlier Swedish study [25]. The gender ratio was more equal in the immigrant group. There was a slight gender difference for $\mathrm{HbA}_{1 \mathrm{c}}$ in the Swedish children, girls having higher $\mathrm{HbA}_{1 \mathrm{c}}$. This finding may seem surprising as we could 
not see the same in immigrant girls. The lower BMI-SDS and the tendency to a higher proportion of weight loss in the Swedish cohort were somewhat surprising as we had expected the opposite, the immigrant children coming later for diagnosis. On the other hand, it is possible that the immigrant children being a complex group of diverse ethnicity had higher BMI before diabetes onset than the Swedish children and therefor still presenting a higher BMI after onset.

Immigrant families possess poorer social living conditions, but socio-demographic conditions do not seem to explain the inferior metabolic situation at diabetes onset. One can assume that shortcomings in understanding Swedish, the immigrant parents caring for more children and the fact that they come from a different cultural background, might explain why their offspring has inferior metabolic status at T1D onset. We have not been able to investigate those issues in our study, but this has been addressed in other studies [26, 27]. Immigrant families often originate from countries where T1D occurs more seldom and are therefore less likely to be familiar with early symptoms of this condition. The Parma campaign successfully completed in Italy to diminish the incidence of diabetes keto-acidosis is an admirable example of informing the public about severe disease symptoms, although it does not address immigrant families specifically [28]. The problem of handling patients and families with different cultural background and language is a demanding task with the aim of equalising the metabolic control of T1D between ethnic groups and Swedes [29].

Finland, the only country with a higher incidence than Sweden, is included in the group of immigrants, this may have an impact on the results, the differences seen being less obvious. However, when we performed a separate calculation excluding the Nordic countries the results became the same, figures not shown. Genetic explanations for the worse metabolic start could not be completely ruled out, but seem unlikely. The factor of being born in Sweden, was not addressed in this study, but in previous studies this was presented as a 
reason for increased risk of incurring T1D among immigrant children but for the conditions at onset this factor seems irrelevant $[9,30]$. Epigenetic factors are probably active in the pathogenesis of T1D but for the metabolic status at diabetes onset this is more elusive [7]. In fact the majority $(72.9 \%)$ of the immigrant children were born in Sweden. The immigrant cohort comprises children from very diverse ethnic and geographic regions, so their cultural and living conditions are most disparate and this fact delimits etiological associations related to separate regions or countries.

The major strength of this study is the large, representative and ethnically diverse study population made possible by the high quality and wide coverage of the Swedish national registers and the comparably high immigration rate into the Swedish society in recent decades. The completeness, covering all children with diabetes in an entire country of more than 9.5 million people for more than 10 years is also a considerable strength. The unique personal identification number (PIN) for every resident in Sweden makes it possible to link socio-demographic data from national registers held by Statistics Sweden not only for the patient but for all family members [14]. There may be a few immigrant families that have moved abroad and thus are missing in the national registries, but this hardly affects the results. The immigrant populations living in Sweden are not necessarily equivalent to the ones in the country of origin. The fact that families from foreign countries with children suffering from a chronic disease tend to refrain from emigration, the healthy migrant effect, could have an impact on the results. This study addresses however the conditions at diabetes onset and not the risk of developing T1D and the comparison with indigenous Swedish peers living in the country of origin is perhaps not crucial in that point.

The present observational study using the influence of migration as a very broad exposure involving cultural, lifestyle, genetic and epigenetic factors delimits the chances of finding specific associations and rules out causality. There is reason to believe that the modern 
affluent society, nowadays more prevalent worldwide, increases beta cell stress, modulated by factors above including nutrition and immunity [7]. However, the disparities seen in metabolic conditions at diabetes onset in the present study are perhaps only partly explained by social and cultural stress and may rather be due to linguistic and other cultural differences. Further studies are needed. It would, if possible, be interesting to see the effect of "reverse" migration from high-incidence to low-incidence countries, compare the results and eventually discover keys to protective factors. For the near future, it would be interesting to see whether the differences in metabolic conditions at T1D onset found in this study, will prevail after some years of treatment.

\section{Acknowledgements}

This study was funded by the Centre for Clinical Research Sörmland, Uppsala University, Sweden and the Swedish Child Diabetes Foundation (Barndiabetesfonden), Linköping, Sweden.

The authors declare no conflict of interest.

\section{Contribution statement:}

US designed the study, collected the data, made statistical analyses, interpreted the results and wrote the manuscript.

$\mathrm{J} \AA$ contributed to the design of the study, the interpretation of the results and participated in writing the manuscript.

USa contributed to the design of the study, collecting the data, the interpretation of the results and participated in writing the manuscript.

LS contributed to the collecting of data, made the statistical analyses and participated in writing the manuscript.

All four authors conscent to the aproval of the manuscript. 


\section{Tables}

Table 1. Clinical characteristics of children with type 1 diabetes at onset; the first three on top are matched

\begin{tabular}{|c|c|c|c|c|c|}
\hline & \multicolumn{2}{|c|}{$\begin{array}{l}\text { Immigrants } \\
\mathrm{n}=879\end{array}$} & \multicolumn{3}{|l|}{$\begin{array}{l}\text { Swedes } \\
\mathrm{n}=2627\end{array}$} \\
\hline & Median & I-q range ${ }^{a}$ & Median & I-q range ${ }^{a}$ & $\mathrm{p}$ \\
\hline Female sex (\%) & 49.1 & & 49.1 & & 1.000 \\
\hline Year of onset & 2004 & 8 & 2004 & 8 & 0.986 \\
\hline Age, yrs & 10.2 & 6.7 & 10.5 & 6.9 & 0.432 \\
\hline Maternal age, yrs & 39.0 & 9.3 & 39.0 & 9.0 & 0.448 \\
\hline Paternal age, yrs & 44.0 & 11.0 & 42.0 & 9.0 & $<0,001$ \\
\hline Height, cm & 145.6 & 38 & 145.8 & 40.1 & 0.501 \\
\hline Weight, kg & 34.0 & 27.9 & 34.3 & 26.0 & 0.769 \\
\hline Weight loss (\%) ${ }^{b}$ & 25.8 & & 30.2 & & 0.054 \\
\hline BMI, SDS & -0.18 & 2.21 & -0.52 & 1.97 & 0.027 \\
\hline P-glucose, $\mathrm{mmol} / \mathrm{L}$ & 24.0 & 10.5 & 25.0 & 9.7 & 0.20 \\
\hline $\mathrm{HbA} 1 \mathrm{c}, \mathrm{mmol} / \mathrm{mol}$ & 94 & 36 & 88 & 35 & 0.005 \\
\hline pH (capillary blood) & 7.35 & 0.1 & 7.37 & 0.07 & $<0.001$ \\
\hline $\mathrm{pH}<7.30(\%) \mathrm{b}$ & 25.8 & & 16.4 & & $<0.001$ \\
\hline Bicarbonate, $\mathrm{mmol} / \mathrm{L}$ & 22.0 & 7.0 & 23.0 & 5.3 & 0.001 \\
\hline $\begin{array}{l}\text { Diastolic blood-pressure, } \\
\mathrm{mm} \mathrm{Hg}\end{array}$ & 66.0 & 12 & 65 & 12 & 0.789 \\
\hline $\begin{array}{l}\text { Systolic blood-pressure, } \\
\mathrm{mm} \mathrm{Hg}\end{array}$ & 109 & 20 & 110 & 17 & 0.563 \\
\hline${ }^{\mathrm{a}}$ Inter-quartile range (75tr & percen & & & & \\
\hline
\end{tabular}


Table 2. Maternal socio-demographic status at child's diabetes onset

\begin{tabular}{|c|c|c|c|}
\hline & Immigrants & Swedes & \multirow[b]{2}{*}{$\mathrm{p}$} \\
\hline & $\mathrm{N}=879$ & $\mathrm{~N}=2627$ & \\
\hline \multicolumn{4}{|l|}{ Marital status, $\%$} \\
\hline married/ attached & 72.5 & 79.8 & \\
\hline single & 27.5 & 20.2 & $<0.001$ \\
\hline \multicolumn{4}{|l|}{ Education, \% } \\
\hline pre-college $(<9$ years $)$ & 34.8 & 9.7 & \\
\hline college & 41.1 & 53.9 & \\
\hline university & 24.1 & 36.4 & $<0.001$ \\
\hline Social welfare, $\%$ & 30.8 & 4.3 & $<0.001$ \\
\hline Employment, \% & 45.9 & 84.6 & $<0.001$ \\
\hline \multicolumn{4}{|l|}{ Housing, \% } \\
\hline renting apartment & 63.3 & 19.0 & \\
\hline own house & 36.7 & 81.0 & $<0.001$ \\
\hline \multicolumn{4}{|l|}{ Number of children, $\%$} \\
\hline 1 & 7.8 & 7.6 & \\
\hline $2-3$ & 55.2 & 78.9 & \\
\hline$>3$ & 37.0 & 13.5 & $<0.001$ \\
\hline \multicolumn{4}{|l|}{ Birth order, \% } \\
\hline 1st without siblings & 7.8 & 7.6 & \\
\hline 1st with siblings & 26.8 & 35.2 & \\
\hline$\geq 2 \mathrm{nd}$ & 65.3 & 57.3 & $<0.001$ \\
\hline
\end{tabular}

Group comparisons by Chi-square test 
Table 3. Region/country of origin of the immigrant parents and country of birth of their children

Country of origin

$$
\text { mother }
$$

father

child $^{a}$

$\mathrm{N}(\%)$

$\mathrm{N}(\%)$

$\mathrm{N}(\%)$

Finland

$123(14.0)$

$112(12.7)$

$10(1.1)$

Other Nordic

$37(4.2)$

33 (3.8)

14 (1.6)

Western Europe/USA

$18(2.0)$

$22(2.5)$

$16(1.8)$

Former Yugoslavia

108 (12.3)

$111(12.6)$

$41(4.7)$

East/South Europe

$72(8.2)$

$47(5.3)$

$18(2.0)$

Iraq

147 (16.7)

$160(18.2)$

$73(8.3)$

East Asia

$42(4.8)$

$38(4.3)$

$15(1.7)$

South Asia

137 (4.8)

140 (15.9)

23 (2.6)

Somalia

67 (7.6)

66 (7.5)

$11(1.3)$

Other Africa

98 (11.1)

109 (12.4)

$8(0.9)$

Latin America

$25(2.8)$

$28(3.2)$

$5(0.6)$

Other countries

$5(0.6)$

$13(1.5)$

$4(0.4)$

All

$879(100.0)$

879 (100.0)

${ }^{\mathrm{a}} 641$ (72.9\%) were born in Sweden 


\section{References}

1. Group DP. Incidence and trends of childhood Type 1 diabetes worldwide 19901999. Diabet Med 2006; 23:857-866.

$2 . \quad$ Dahlquist GG, Nystrom L, Patterson CC. Incidence of type 1 diabetes in Sweden among individuals aged 0-34 years, 1983-2007: an analysis of time trends. Diabetes Care $2011 ; \mathbf{3 4 : 1 7 5 4 - 1 7 5 9 .}$

3. Ehehalt S, Dietz K, Willasch AM, Neu A. Prediction model for the incidence and prevalence of type 1 diabetes in childhood and adolescence: evidence for a cohortdependent increase within the next two decades in Germany. Pediatr Diabetes 2012; 13:1520 .

4. Gyurus EK, Patterson C, Soltesz G. Twenty-one years of prospective incidence of childhood type 1 diabetes in Hungary--the rising trend continues (or peaks and highlands?). Pediatr Diabetes 2012; 13:21-25.

5. Svensson J, Carstensen B, Molbak A, Christau B, Mortensen HB, Nerup J, et al. Increased risk of childhood type 1 diabetes in children born after 1985. Diabetes Care 2002; 25:2197-2201.

6. $\quad$ Knip M, Veijola R, Virtanen SM, Hyoty H, Vaarala O, Akerblom HK. Environmental triggers and determinants of type 1 diabetes. Diabetes 2005; 54 Suppl 2:S125136.

7. Oresic M, Simell S, Sysi-Aho M, Nanto-Salonen K, Seppanen-Laakso T, Parikka V, et al. Dysregulation of lipid and amino acid metabolism precedes islet autoimmunity in children who later progress to type 1 diabetes. $J$ Exp Med 2008; 205:29752984.

8. Hjern A, Soderstrom U. Parental country of birth is a major determinant of childhood type 1 diabetes in Sweden. Pediatr Diabetes 2008; 9:35-39.

9. Soderstrom U, Aman J, Hjern A. Being born in Sweden increases the risk for type 1 diabetes - a study of migration of children to Sweden as a natural experiment. Acta Paediatr 2012; 101:73-77.

10. Delli AJ, Lindblad B, Carlsson A, Forsander G, Ivarsson SA, Ludvigsson J, et al. Type 1 diabetes patients born to immigrants to Sweden increase their native diabetes risk and differ from Swedish patients in HLA types and islet autoantibodies. Pediatr Diabetes 2010 .

11. Cadario F, Vercellotti A, Trada M, Zaffaroni M, Rapa A, Iafusco D, et al. Younger age at diagnosis of type 1 diabetes mellitus in children of immigrated families born in Italy. J Endocrinol Invest 2004; 27:913-918.

12. Hanberger L, Samuelsson U, Bertero C, Ludvigsson J. The influence of structure, process, and policy on $\mathrm{HbA}(1 \mathrm{c})$ levels in treatment of children and adolescents with type 1 diabetes. Diabetes Res Clin Pract 2012; 96:331-338.

13. Hanberger L, Samuelsson U, Lindblad B, Ludvigsson J. A1C in children and adolescents with diabetes in relation to certain clinical parameters: the Swedish Childhood Diabetes Registry SWEDIABKIDS. Diabetes Care 2008; 31:927-929.

14. Ludvigsson JF, Otterblad-Olausson P, Pettersson BU, Ekbom A. The Swedish personal identity number: possibilities and pitfalls in healthcare and medical research. Eur $J$ Epidemiol 2009; 24:659-667.

15. Wikland KA, Luo ZC, Niklasson A, Karlberg J. Swedish population-based longitudinal reference values from birth to 18 years of age for height, weight and head circumference. Acta Paediatr 2002; 91:739-754.

16. Hanas R, John G. 2010 consensus statement on the worldwide standardization of the hemoglobin A1C measurement. Diabetes Care 2010; 33:1903-1904. 
17. Nordin G, Dybkaer R. Recommendation for term and measurement unit for "HbA1c". Clin Chem Lab Med 2007; 45:1081-1082.

18. Lindblad B, Nordin G. External quality assessment of HbA1c and its effect on comparison between Swedish pediatric diabetes clinics. Experiences from the Swedish pediatric diabetes quality register (Swediabkids) and Equalis. Clin Chem Lab Med 2013:1-8. 19. Samuelsson U, Lindblad B, Carlsson A, Forsander G, Ivarsson S, Kockum I, et al. Residual beta cell function at diagnosis of type 1 diabetes in children and adolescents varies with gender and season. Diabetes Metab Res Rev 2013; 29:85-89.

20. The Swedish pediatric diabetes quality register, (SWEDIABKIDS) (2010). https://www.ndr.nu/ndr2/.

21. Viswanathan V, Sneeringer MR, Miller A, Eugster EA, DiMeglio LA. The utility of hemoglobin A1c at diagnosis for prediction of future glycemic control in children with type 1 diabetes. Diabetes Res Clin Pract 2011; 92:65-68.

22. Shalitin S, Phillip M. Which factors predict glycemic control in children diagnosed with type 1 diabetes before 6.5 years of age? Acta Diabetol 2012; 49:355-362.

23. Samuelsson U, Steineck I, Gubbjornsdottir S. A high mean-HbA1c value 3-15 months after diagnosis of type 1 diabetes in childhood is related to metabolic control, macroalbuminuria, and retinopathy in early adulthood-a pilot study using two nation-wide population based quality registries. Pediatr Diabetes 2013.

24. The effect of intensive treatment of diabetes on the development and progression of long-term complications in insulin-dependent diabetes mellitus. The Diabetes Control and Complications Trial Research Group. N Engl J Med 1993; 329:977-986.

25. Hanas R, Lindgren F, Lindblad B. Diabetic ketoacidosis and cerebral oedema in Sweden--a 2-year paediatric population study. Diabet Med 2007; 24:1080-1085.

26. Povlsen L. How can we adapt education for children across different countries? Horm Res 2002; 57 Suppl 1:72-74.

27. Povlsen L, Olsen B, Ladelund S. Educating families from ethnic minorities in type 1 diabetes-experiences from a Danish intervention study. Patient Educ Couns 2005; 59:164-170.

28. Vanelli M, Scarabello C, Fainardi V. Available tools for primary ketoacidosis prevention at diabetes diagnosis in children and adolescents. "The Parma campaign". Acta Biomed 2008; 79:73-78.

29. Povlsen L, Ringsberg KC. Learning to live with a child with diabetes--problems related to immigration and cross-cultural diabetes care. Scand J Caring Sci 2009; 23:482-489. 30. Delli AJ, Lindblad B, Carlsson A, Forsander G, Ivarsson SA, Ludvigsson J, et al. Type 1 diabetes patients born to immigrants to Sweden increase their native diabetes risk and differ from Swedish patients in HLA types and islet autoantibodies. Pediatr Diabetes 2010; 11:513-520. 